* Doutorado em Direito pela Universidade Federal da Bahia. Mestrado em Direito pela Universidade Federal da Bahia. Mestrado em Ciência da Informação pela Universidade Federal da Bahia. Especialista em Processo Penal pelo Instituto Brasileiro de Ciências Criminais/ Universidade de Coimbra. Especialista em Contabilidade Gerencial pela Universidade Federal da Bahia. Graduada em Direito pela Faculdade Baiana de Ciências. Graduada em Ciências Contábeis pela Fundação Visconde de Cairu. Advogada. Professora aleportella@hotmail.com

\section{Direito de Punir: Reflexões sobre os Pressupostos e os Fins da Pena}

\author{
The Rigth to Punish: Considerations \\ on the Penalty's Finality
}

\section{Alessandra Matos Portella*}

Como citar: PORTELLA, Alessandra Matos. Direito de punir: reflexos sobre os pressupostos e os fins da pena. Revista do Direito Público, Londrina, v. 12 , n. 3, p.16-57, dez. 2017. DOI: 10.5433/1980-511X2017v12n3p16. ISSN: $1980-511 X$.

Resumo: Este artigo tem por objetivo refletir sobre os pressupostos e os fins da pena, no âmbito do Estado Democrático de Direito, tendo por eixo norteador a dignidade da pessoa humana. Buscar-se-á compreender a intervenção estatal para a aplicação da pena a partir de paradigmas referentes à culpabilidade material ou às finalidades da pena, realizando, para tanto, uma digressão histórica acerca das teorias fundamentadoras da culpabilidade. Por outro lado, refletir-se-á acerca das teorias deslegitimadoras da pena para contrapô-las às teorias legitimadoras da sanção penal de modo a responder a uma das indagações mais controversas relativas à história do homem, a saber: por que punir?

Palavras-Chaves: Culpabilidade. Pena. 
Dignidade da pessoa humana.

Abstract: This paper comments on the finality of the penalty, from the perspective of the democratic state's rule of law and the principle of the human person's dignity. Moreover, this study seeks to understand state intervention when imposing sentences, within both paradigms of guilt and the punishment's finality. With this objective, this research critically analyzes the fundamental theories of culpability. Sequentially, this paper explores theories of punishment and tries to align them with current theories of criminal penalties in order to address one of the most controversial questions in human history: why punish?

Keywords: Guilty. Penalty. Human Dignity. 


\section{INTRODUÇÃO}

O marco conceitual da culpabilidade se dá, inicialmente, no esplendor do século XVIII, influenciada pelo movimento Iluminista, em pleno Século das Luzes, quando os denominados Reformadores - dentre eles, Beccaria, Montesquieu, Carrara, Bentham, etc. - denunciaram a barbárie dos suplícios corporais, espinha dorsal do Direito Penal dominante na Idade Média.

Surgiu, inicialmente, como consequência lógica do princípio da legalidade, o qual propugna que não pode existir crime, sem lei anterior clara, escrita e certa que o defina. Porém, uma vez criado pelo Legislador, o crime passa a existir no ordenamento jurídico vigente, consoante o princípio da legalidade (art. $5^{\circ}$, inc. XXXIX, CF e art. $1^{\circ}$, $\mathrm{CP})$ e, a partir de então, a culpabilidade de alguém pode ser declarada, acaso haja afronta à respectiva lei penal em vigor, é isto o que se extrai do princípio "nullum crime sine culpa". Desta forma,

[...] a culpabilidade fundamenta-se no conhecimento (real ou possível) do tipo de injusto, logo, o princípio da culpabilidade pressupõe ou contém o princípio da legalidade como definição escrita, prévia, estrita e certa do tipo de injusto (SANTOS, 2010, p. 24).

Ainda conforme Santos (2010, p. 24):

[...] o princípio da culpabilidade, expresso na fórmula nulla poena sine culpa, é o segundo mais importante instrumento de proteção individual no moderno Estado Democrático de Direito 
porque proíbe punir pessoas sem os requisitos do juízo de reprovação.

Assim, o princípio da culpabilidade, ao lado do princípio da legalidade, constitui-se um dos mais importantes instrumentos garantidores da dignidade da pessoa humana num Estado Democrático de Direito. Achenbach (apud PÉREZ MANZANO, 1990) afirma que, como princípio, a culpabilidade possui hierarquia constitucional, sendo necessários princípios metajurídicos para explicá-la, advindos, por exemplo, da filosofia, antropologia, sociologia, etc.

Enquanto norma constitucional que é, a culpabilidade assegura direitos fundamentais ligados à dignidade da pessoa humana, valor maior num Estado Democrático de Direito, consoante se depreende do disposto no art. $1^{\circ}$, inc. III, da Carta Magna brasileira, tendo tratamento, inclusive, de cláusula pétrea, ou seja, jamais podendo ser abolida ou mesmo minimizada, em respeito ao art. $60, \S 4^{\circ}$, da Constituição Federal.

Entretanto, para além deste viés principiológico, a culpabilidade também representa um juízo de reprovação do agente e, nesta acepção, acaba instrumentalizando-se como fundamento da pena, possuindo estrutura dogmático-penal, fundamentando, inclusive, os casos em que a sanção não é aplicada ou é atenuada, levando-se em consideração sempre as decisões legislativas do Estado, baseadas na experiência social.

Mas o que, exatamente, vem a ser este juízo de reprovação? Quando o Estado está legitimado para aplicar a pena a alguém? Quando poderá reprovar o comportamento de um cidadão? A resposta a estes questionamentos perpassa, necessariamente, pelas teorias fundamentadoras da culpabilidade, como exposto adiante.

Quem primeiro tratou culpabilidade como reprovabilidade 
foi Frank (2004) pois, antes dele, culpabilidade era apenas um liame subjetivo que ligava o autor ao fato punível, sendo representada, portanto, pelo dolo e pela culpa em sentido estrito (imprudência), haja vista a imputabilidade ser tão-somente um pressuposto da culpabilidade.

Fran Von Lizst é tido como representante desta teoria causalnaturalista da ação, pois entendia que o injusto penal era um processo causal originário, representado por impulsos voluntários, sendo desprovida de conteúdo, uma vez que o dolo e a culpa stricto sensu pertenciam à culpabilidade, sendo esta um nexo psicológico indispensável entre o autor e o fato punível, denominada, por isso, de teoria psicológica da culpabilidade.

Consoante Welzel (2004, p. 90-91),

[...] na dogmática moderna separavam-se, em princípio, o "externo" do "interno", o "objetivo" do "subjetivo". Todo o externo-objetivo era associado à antijuridicidade e todo o internosubjetivo à culpabilidade; a culpabilidade deveria ser "a relação anímica entre o autor e o resultado". [...] Em que deveria consistir a relação anímica entre o autor e resultado na culpa inconsciente? A culpa inconsciente foi a primeira dificuldade com que se deparou a concepção psicológica da culpabilidade.

Foi Frank (2004) quem introduziu um elemento valorativo à culpabilidade, quando afirmou ser esta uma reprovabilidade da conduta do agente, já que como imputável - mentalmente desenvolvido e são, conhecia a ilicitude da conduta e podendo atuar de modo diverso, ou seja, conforme o Direito, preferiu escolher um comportamento antijurídico, 
sendo, por isso, culpável. Desta forma, inaugura a teoria normativa da culpabilidade, situando a imputabilidade não mais como pressuposto, mas como elemento mesmo desta, que, ao lado do dolo e da culpa stricto sensu, tinha o condão de tornar o homem culpável.

Extrai Frank essa conclusão a partir da análise do estado de necessidade,

[...] pois a exclusão da responsabilidade neste caso não pode reconduzir-se ao esquema clássico da culpabilidade, senão que se deve levar em consideração como anormais as circunstâncias concomit-antes do fato. [...] Para Frank, em consequência, a culpabilidade se compõe de três elementos: imputabilidade, dolo ou culpa e a normalidade das circunstâncias do fato em que o autor tenha atuado. Como característica englobante destes três elementos, assinala Frank a reprovabilidade (PÉREZ MANZANO, 1990, p. 79-80).

Ao lado de Frank (2004), destaca-se também GoldschmIdt (2002), que deu a sua contribuição à teoria normativa da culpabilidade quando diferenciou norma jurídica de norma de dever. Para ele, a norma jurídica relacionava-se com o injusto, por isso era de caráter objetivo e geral, enquanto que a norma de dever se relacionava com a culpabilidade, logo, de caráter individual e subjetiva, tendo, por isso, este autor, conceituado a culpabilidade como uma contrariedade ao dever, sendo este o seu elemento normativo.

Freudenthal, assim como Frank (2004) e Goldschimidt (2002), também contribuiu sobremaneira para a teoria normativa da culpabilidade, 
quando inseriu o elemento exigibilidade, ao lado da reprovabilidade, ou seja, para ele, era preciso verificar as circunstâncias concretas em que atua o autor do injusto, se estaria ele diante de circunstâncias normais ou anormais, haja vista o Estado só poder exigir dele uma atuação conforme o Direito caso este esteja em uma situação de normalidade. Deparandose o autor diante de situações excepcionais, como, por exemplo, um estado de necessidade exculpante, jamais poderá ser-lhe exigido que aja em conformidade com o ordenamento jurídico, devendo-lhe, assim, ser declarada sua inculpabilidade.

Por isso, para Freudenthal, para se cobrir o espaço entre culpabilidade e inculpabilidade é imperioso recorrer ao princípio geral da exigibilidade. Assim sendo, ao lado do juízo de reprovação, é preciso também verificar se pode o autor na situação fática que se encontra pode atuar de outra maneira.

Por isso, para Freudenthal, a exigibilidade deve perpassar por um juízo individual e não objetivo-geral como propugnado pela doutrina dominante. Por meio deste juízo subjetivo-individual que se pode determinar a culpabilidade do autor, levando em consideração as circunstâncias concretas, postura esta refletida a posteriori na teoria finalista de Welzel, mais especificamente em um de seus elementos da culpabilidade, a saber: exigibilidade de conduta diversa. Coadunando que este pensamento de Freudenthal, Mello (2010, p. 322) afirma que:

[...] uma concepção material da culpabilidade, para que se respeite a dignidade humana, demanda uma individualização, um exame das circunstâncias individualizadoras presentes no sujeito e na situação, que interferem no fundamento da imputação e na sua graduação. 
Por esta razão, tantas críticas são feitas ao paradigma do "homem médio".

Porém, apesar de seu esforço original individualizador da conduta do sujeito, o que prevaleceu mesmo foi a teoria generalizante, foi o conceito do "cidadão tipo médio" inspirado por Eberhard Schmidt e Edmund Mezger. Em razão disso, questiona-se o comportamento de uma pessoa considerada mediana, colocando-a abstratamente na mesma posição do autor do injusto penal, de forma a verificar se também esta pessoa se comporta do mesmo jeito que o autor do fato punível.

Em sendo a resposta positiva, então o Estado deve exculpar a conduta do autor, visto que não pode ele agir de outro modo, pois qualquer um, em sua situação, agiria da mesma forma; porém, sendo negativa a resposta, o Estado deve declarar a culpabilidade do autor, haja vista ter podido ele atuar de forma diversa, não o fazendo por livre vontade.

O que determina, portanto, o juízo de reprovação e a respectiva constatação da culpabilidade, é a experiência do julgador, ou seja, a utilização do raciocínio analógico; o que se reprova, em realidade, é que o autor se desviou da média das pessoas, independentemente de uma análise mais acurada acerca do poder ou não atuar de outro modo, dentro das circunstâncias fáticas em que se encontrava o autor diante do fato típico e antijurídico.

Percebe-se, assim, que a teoria normativa da culpabilidade parte do pressuposto que o homem é possuidor de livre-arbítrio, podendo determinar-se segundo sua própria vontade. Assim sendo, podendo e devendo motivar-se conforme a norma prefere atuar contrariamente a ela, sendo a culpabilidade, por isso, equiparada a exigibilidade, ou seja, a capacidade do Estado de exigir de uma pessoa imputável uma resposta 
determinada, que é a sua atuação em conformidade com o ordenamento jurídico.

Desta forma, a pena se justifica, para os defensores do livrearbítrio (indeterministas), na medida em que representa uma retribuição de um mal a alguém que agiu com um comportamento antijurídico podendo e devendo ter atuado conforme o ordenamento jurídico, uma vez que é um ser capaz de autodeterminação, logo, de ser motivado pela norma; desta forma, utiliza a culpabilidade para fundamentar a imposição da sanção penal, bem como, para, posteriormente, fixar o limite desta pena.

Esta tese, entretanto, foi rechaçada pela corrente determinista, pelos adeptos da Escola Positivista, por entenderem que o livre-arbítrio é indemonstrável, logo, a-científico, não podendo servir de parâmetro para declarar a culpabilidade ou inculpabilidade de alguém. Ademais, “[...] não se pode demonstrar se uma pessoa concreta em uma determinada situação podia atuar de outra forma, pois a base do experimento, colocar a mesma pessoa na mesma situação, é impossível." (PÉREZ MANZANO, 1990, p. 93).

Desta forma, em lugar da culpabilidade propõem a periculosidade, pois entende esta corrente científica que o homem criminoso é um ser humano patologicamente diferente dos demais, "anormal", logo, propenso ao crime.

O crime para a escola positivista existia de per si, era um ser ôntico, natural e o criminoso era alguém patológico, anormal, que se diferenciava biologicamente dos demais membros da sociedade, por isso, por exemplo, “[...] para Lombroso, o homem era predeterminado biologicamente a cometer atos delituosos, pressionados por fenômeno de ordem endógena ou exógena." (SANTOS, 2006, p. 32). 
Ocorre, todavia, que também esta corrente determinista, representada pelo positivismo, não consegue demonstrar cientificamente a veracidade das suas propostas teóricas, sendo, pois, também refutada por alguns autores, pois,

[...] como afirma Nowakowski, a questão da liberdade não pode ser decidida empiricamente nem a favor do determinismo, nem a favor do indeterminismo; a decisão será em todo caso uma opinião pessoal. A aceitação de uma ou outra postura será sempre uma suposição (PÉREZ MANZANO, 1990, p. 105).

Mas, se o juízo de reprovabilidade do Estado se centra na exigibilidade de conduta diversa de alguém, como reprovar uma pessoa se não é possível provar, demonstrar no caso concreto, se ela podia ou não atuar de modo diverso de como atuou? Como declarar sua culpabilidade, ante a impossibilidade de demonstrar "o poder atuar de outro modo", sendo este o fundamento material da culpabilidade?

Além dessa crítica, podem-se citar outras conforme aduz Pérez Manzano (1990, p. 95-96), a saber:

a) se argumenta que a reprovação da culpabilidade tem caráter ético e que não é missão do Direito Penal realizar juízos éticos sobre a conduta do delinquente; b) desde o ponto de vista dogmáticosistemático se achava haver impedido de perceber com maior claridade que o dolo forma parte do tipo de delito doloso e que o caso fortuito e o estado de necessidade por conflito entre bens iguais afetam a antijuridicidade desprezando-a; c) a respeito da teoria da pena se argumenta a 
incapacidade da culpabilidade para servir de fundamente para pena e as teorias retributivas sua incapacidade para servir de limite ao poder punitivo em vista de sua impossibilidade de medição e, inclusive, se alude que os critérios que servem para a medição da pena estão fora da culpabilidade, portanto, são estes outros critérios que limitam o poder punitivo estatal.

Em decorrências dessas severas críticas realizadas pela doutrina, Welzel (2004) irá desenvolver um trabalho sistemático de extrema importância sobre o fundamento da culpabilidade, lhe atribuindo novas feições, a partir de meados do século XX, tendo retirado da culpabilidade os elementos não normativos, deixando-lhe apenas a imputabilidade, $o$ potencial conhecimento da antijuridicidade e a exigibilidade de conduta diversa, sendo esta presumida de forma geral para os imputáveis, haja vista sua indemonstrabilidade.

Apesar de não enfrentar o problema da "exigibilidade de conduta diversa", a contribuição de Welzel (2004) para a teoria do delito se dá na medida em que considera a culpabilidade como uma valoração negativa da vontade da ação, não a considerando como a vontade da ação em si, como fazia os seus antecessores, separando, desta forma, o objeto da valoração da valoração do objeto.

A vontade de ação, representada pelo dolo (objeto da valoração), passa, então, a pertencer ao injusto, à tipicidade, enquanto que à culpabilidade passa a representar tão-somente um juízo de reprovação individual que se faz a respeito da conduta do autor (valoração negativa do objeto), composto unicamente de elementos normativos, daí essa teoria ser denominada de teoria normativa pura da culpabilidade, prevalecente 
até o presente momento na teoria do delito inserido num sistema finalista da ação.

Assim a culpabilidade passa a ter caráter eminentemente normativo, uma vez que não se trata de declará-la, mas apenas de imputála e, para proceder a imputação, se utiliza do método do "homem médio", utiliza-se o raciocínio analógico para se saber, se naquelas circunstâncias determinadas, um homem mentalmente são (considerado abstratamente), de inteligência mediana, poderia se motivar perante a norma penal. Em caso positivo então se imputa a culpabilidade ao autor do fato típico e antijurídico, sendo negativa a resposta, exclui-se a culpabilidade ou a atenua, segundo padrões definidos pelo Legislador.

Esta graduação da culpabilidade acaba por torná-la também limite da pena, estando ela presente dentre as circunstâncias judiciais previstas pelo art. 59 do Código Penal brasileiro, de imprescindível observância para a fixação da pena-base pelo magistrado. Enquanto parâmetro judicial na dosimetria da pena a culpabilidade possui graus de intensidade, devendo o juiz dosá-la de modo a estabelecer uma pena proporcional ao delito cometido.

\section{ANÁlise da CULPABILIDAde PELA PERSPECTIVA DE JAKOBS E ROXIN}

Antes de iniciar a exposição acerca do conceito de culpabilidade esposado por Jakobs e Roxin, se faz necessário uma alusão ao sistema funcionalista ou teleológico-funcional do delito, uma vez que ambos os doutrinadores situam-se no interior desta concepção do Sistema Jurídico-Penal.

O funcionalismo defende a construção do sistema penal não 
a partir de dados ontológicos, mas a partir dos fins do Direito Penal, notadamente sob a ótica da prevenção geral positiva (Jakobs e Roxin) e da prevenção especial positiva e negativa (Roxin), rechaçando a teoria retributiva.

Segundo Greco (2017, p. 134-135) o que permeia o sistema funcionalista é justamente a tensão existente entre liberdade do indivíduo versus proteção de bem jurídico, na medida em que:

[...] quanto mais exigir para o dolo, mais acrescenta na liberdade dos cidadãos, às custas da proteção dos bens jurídicos; e quanto menos exigências formular para que haja dolo, mais protege bens jurídicos, e mais limita a liberdade dos cidadãos.

Gunther Jakobs entende que a finalidade do Direito Penal não é a proteção de bens jurídicos, mas a vigência na norma penal, sendo esta necessária para a manutenção da ordem social. A punição nesta perspectiva não se legitima a partir de uma lesão a um bem jurídico, mas sua necessidade se dá para reafirmar a norma jurídica violada com a infração penal de modo a reafirmar os valores sociais.

Por isso, sua leitura da culpabilidade se dá a partir dos fins da pena, ou seja, a partir da manutenção do ordenamento jurídico. Assim sendo, a culpabilidade é “[...] responsabilidade por um déficit de motivação jurídica dominante em um comportamento antijurídico que afeta a confiança geral da norma. Por isso, a culpabilidade designa uma falta de fidelidade ao direito" (BUSTOS RAMÍREZ; HORMAZÁBAL MALARÉE, 1999, p. 321).

Entretanto, este seu conceito de culpabilidade serve tão-somente 
para o que ele chama de Direito Penal do cidadão, uma vez que o denominado Direito Penal do inimigo visa afastar o perigo, dirigindo-se a fatos futuros, ainda não cometidos, tendo em vista o valor "segurança da sociedade". Nesta seara a culpabilidade não é levada em conta, apenas e tão-somente os fins da pena, sob a ótica defendida por ele que é da prevenção geral positiva.

Jakobs afirma que a:

[...] função manifesta da pena no direito penal do cidadão é a contradição - conforme teoria da prevenção geral positiva, defendida pelo doutrinador - enquanto que a função do direito penal do inimigo é a "eliminação de um perigo (apud MORAES, 2008, p. 27).

A questão da manutenção do ordenamento jurídico e, consequentemente, da própria sociedade, é tão forte em Jakobs, que se pode extrair da sua teoria que não há nada

[...] além do ordenamento jurídico, nem sequer a pessoa. A pessoa se reconhece e vale enquanto é parte do ordenamento e participa de suas características. É pura apologia do sistema, não há barema para averiguar que estabiliza a confiança do ordenamento nem tampouco há possibilidade de processar o conflito de modo diferente, que substitua a pena (BUSTOS RAMÍREZ; HORMAZÁBAL MALARÉE, 1999, p. 321).

Daí porque Jakobs é considerado o representante da concepção funcionalista radical, diferentemente de Roxin que, apesar de também ser 
considerado funcionalista, incorpora em sua teoria elementos valorativos compatíveis com o Estado Democrático de Direito, notadamente os ligados à dignidade da pessoa humana, fundamento basilar dos Direitos Fundamentais defendidos por ele.

Roxin idealiza um sistema penal teleológico (funcionalista), vinculando o Direito Penal às exigências políticos-criminais do Estado, abrindo um diálogo salutar entre a dogmática e as estratégias políticas de uma determinada sociedade no tocante ao combate da criminalidade.

Para Roxin, as finalidades da punição “[...] são constituídas pela prevenção geral de delitos para terceiros respeitadores da lei e pela prevenção especial para quem cometeu o delito, a fim de que não venha a cometer outros." (BICUDO, 2010, p. 161).

Por isso, diferentemente de Jakobs, não defende a culpabilidade a partir dos fins da pena, mas fundamenta a mesma a partir da "[...] capacidade de autocondução de impulsos psíquicos e a resultante dirigibilidade normativa de um sujeito em uma determinação situação." (BUSTOS RAMÍREZ; HORMAZÁBAL MALARÉE, 1999, p. 325-326).

Portanto, para Roxin, “[...] enquanto a categoria da culpabilidade é necessária para vincular o autor de um delito à prática de um delito, a categoria da prevenção é aquela que delimita, para o julgador, a necessidade de punição" (BICUDO, 2010, p. 173).

Resumindo: em uma sociedade liberal e ordenada segundo o modelo do Estado de Direito, o Direito Penal mais adequado à luta contra o delito não é o Direito Penal da retribuição segundo a culpabilidade, nem um puro Direito Penal da prevenção, mas uma síntese de ambos. Não se pode jamais punir se não houver necessidade de 
prevenção, mas também se não houver culpa. A prevenção no Direito Penal vem limitada pela culpa, mas também a pena só pode ser aplicada nos limites da necessidade e do escopo da prevenção (ROXIN, 2001 apud BICUDO, 2010, p. 173).

Desta forma, constrói ele a categoria da responsabilidade penal que é constituída tanto pela culpabilidade, quanto pelos fins preventivos, significando que a culpabilidade é necessária, mas não suficiente para a imposição de uma sanção penal, haja vista ter que se averiguar, no caso concreto, a real necessidade de aplicação da pena, conforme os fins numa perspectiva de prevenção geral e especial (BUSTOS RAMÍREZ; HORMAZÁBAL MALARÉE, 1999).

\section{ANÁlise da CULPABILIDADE PELA PERSPECTIVA DE BUSTOS RAMÍREZ E HORMAZÁBAL MALARÉE}

Para Bustos Ramírez a culpabilidade é um elemento alheio ao delito, uma vez que este é representado pelo fato típico e antijurídico, sendo à culpabilidade um juízo de valoração concreta, pertencente apenas ao autor do fato punível, uma vez que num Estado de Direito o que se leva em consideração é o fato perpetrado pelo autor, sua antijuridicidade e não a sua personalidade ou características físicas ou psíquicas. A culpabilidade é importante no momento em que fundamenta o castigo do autor e limita a sua pena, impondo-lhe uma sanção.

Bustos Ramírez inova na leitura que faz sobre a culpabilidade na medida em que põe o acento do problema não no homem, no poder se comportar de modo diverso, mas no sistema social, na sua legitimidade 
para poder exigir de um ser humano concreto, em uma determinada situação também concreta, uma resposta conforme a norma.

Diverge, desta sorte, de todas as teorias tradicionais sobre a culpabilidade expostas acima, desde a teoria psicológica da culpabilidade até a teoria normativa pura, como também diverge de Roxin e Jakobs na medida em que "[...] os fins da pena não podem substituir seus pressupostos." (BUSTOS RAMÍREZ; HORMAZÁBAL MALARÉE, 1999, p. 329).

O ponto de partida para a análise da culpabilidade tem que ser o homem concreto em suas relações sociais concretas, já que é a partir daí que se realiza seu comportamento, em que ele desempenha um determinado papel social. Para Bustos Ramírez e Hormazábal Malarée (1999, p. 333) "[...] na medida em que o homem é um ator dentro do processo social, é que o homem pode responder por sua atuação [...]. Somente assim o homem tem capacidade de resposta".

Ele parte do pressuposto de que a consciência construída pelo homem a respeito de si mesmo e de seu papel perante a sociedade advém de suas próprias relações sociais, na medida em que não é uma questão psíquica, mas histórico-social. Por isso a sociedade não pode instituir respostas uniformes, gerais e abstratas, desconsiderando o homem concreto em seu habitat social, sob pena de dar tratamento igual a situações desiguais, indo de encontro a direitos fundamentais norteadores do Estado de Direito.

Por isso, para Bustos Ramírez, culpabilidade não é reprovabilidade, mas responsabilidade pelo comportamento desconforme com o papel social que deveria desempenhar em suas relações sociais concretas. 
Responsabilidade e exigibilidade são dois termos indissoluvelmente unidos. O Estado não pode exigir se não tem proporcionado ou não se dá condições necessárias para que a pessoa possa assumir uma tarefa determinada, exigida também pelo sistema, por exemplo, o respeito à norma (BUSTOS RAMÍREZ; HORMAZÁBAL MALARÉE, 1999, p. 335).

Sua teoria acerca da culpabilidade parte do princípio da autonomia ética da pessoa, sustentando que as ações dos indivíduos se movem no sentido de responder às suas necessidades e que, por isso, o Estado tem a obrigação de desenvolver nelas suas capacidades e, ao mesmo tempo, ajudá-las a romper os obstáculos para possibilitar as respostas esperados pelo sistema social.

Neste sentido, "[...] o problema a debater é que resposta determinada lhe pode exigir o sistema social a uma pessoa determinada a respeito da satisfação de suas necessidades dentro de uma relação social concreta." (BUSTOS RAMÍREZ; HORMAZÁBAL MALARÉE, 1999, p. 335).

Vê-se, então, que Bustos Ramírez inverte a lógica tradicional da culpabilidade, mostrando que a pessoa não está a serviço do sistema social, mas que este está a serviço da pessoa humana, devendo, por isso, possibilitar-lhe condições para satisfazer suas necessidades, de modo a poder exigir-lhe uma resposta determinada.

Não se trata de um juízo das capacidades das pessoas, senão da capacidade do Estado, em definitivo de sua legitimação, para exigir essa resposta à pessoa e para isso o Estado [...] a 
respeito desse indivíduo concreto há de haver promovido as condições para que sua liberdade e igualdade sejam real e efetiva, e removido os obstáculos que impedem ou dificultam sua plenitude, assim como facilitado sua participação na vida política, econômica, cultural e social (BUSTOS RAMÍREZ; HORMAZÁBAL MALARÉE, 1999, p. 336).

Assim, para ele, é preciso que primeiro o sistema social desenvolva nas pessoas uma consciência política, social e econômica, inserindo-as socialmente para, a partir de então, poder exigir delas determinadas respostas à luz do ordenamento jurídico vigente.

A imputação da responsabilidade penal se legitimaria, então, segundo a culpabilidade do agente medido conforme o desenvolvimento de suas capacidades pessoais, sendo o homem responsável na medida em que recebe, a partir de suas interações sociais, condições eficientes para que possa representar seu papel conforme as expectativas do sistema social. Afinal,

[...] não é o mesmo exigir a responsabilidade de uma pessoa em que a vida lhe tem dado todas as oportunidades do que àquela em que lhe tem negado todas. Por isso, a nosso entender, responsabilidade equivale a exigibilidade e as chamadas causas de inimputabilidade e de exculpação não são senão suposições de inexigibilidade, ou seja, suposições em que o Estado não pode exigir responsabilidade a um indivíduo concreto por um fato cometido (BUSTOS RAMÍREZ; HORMAZÁBAL MALARÉE, 1999, p. 126-127). 
Percebe-se, desta forma, que sua leitura acerca da culpabilidade encontra-se ligada umbilicalmente às premissas de um Estado de Direito na medida em que leva em consideração as diferenças materiais/ substanciais das pessoas inseridas num determinado contexto social.

\section{TEORIAS LEGITIMADORAS DA PENA}

A legitimação da pena é recorrente na dogmática penal que, até o presente momento, não pode ser justificada uniformemente, haja vista a diversidade de teorias que defendem a necessidade de aplicação da pena, indo desde a simples retribuição, até a necessidade de prevenção, seja esta geral ou especial.

A teoria retributiva não traz em sua justificativa nenhuma finalidade social em si, ou seja, basta tão-somente que o crime ocorra para que o Estado imponha uma sanção penal ao indivíduo visando retribuir o mal causado por ele quando do cometimento do delito.

A pena, para este conjunto de teorias, é pensada como castigo, reparação ou expiação, e concebida como um fim em si mesmo. Dito de outro modo, a pena esgota sua finalidade com sua própria aplicação, ancorada em sentimentos comunitários de justiça e equidade (MELLO, 2010, p. 337).

Seus principais representantes foram Kant e Hegel, que, apesar de retribucionistas justificam a pena com fundamentações distintas. Para Kant a aplicação da pena é uma necessidade moral, enquanto para Hegel, 
é uma necessidade advinda do próprio Direito, já que o crime representa a negação do Direito e a pena a negação da negação, logo, reafirmação do Direito.

Denominada de teoria absoluta, sustenta a imposição da pena sem nenhuma visão utilitarista, donde advém o imperativo categórico kantiano, a saber: a pena deve ser aplicada ainda que Estado e sociedade não mais existam, devendo ser executado o último assassino que se encontra na prisão, para que ele sofra pelo delito cometido e a culpa do sangue não pese sobre o povo (ROXIN, 1997, p. 82).

Queiroz (2001, p. 24) afirma que o mérito desta corrente teórica "[...] radica no fato de que a pena, deve ter sempre o delito como pressuposto [...], razão pela qual se presta a coibir abusos por parte do Estado na sua graduação".

Para Roxin (1997, p. 84), o mérito:

[...] radica em sua capacidade de impressão psicológico-social, assim como o fato que proporciona um barema para a magnitude da pena. Se a pena deve "corresponder" à magnitude da culpabilidade, está proibido em todo o caso dar um encaminhamento mediante uma penalização drástica em casos de culpabilidade leve. A idéia de retribuição marca, pois, um limite ao poder punitivo do Estado e tem, nessa medida, uma função liberal de salvaguardar a liberdade.

Porém, apesar de apontar este mérito, Roxin (1998, p. 19) não defende a teoria retributiva da pena num Estado Democrático de Direito, “[...] porque deixa na obscuridade os pressupostos da punibilidade, porque não estão comprovados os seus fundamentos e porque, como 
profissão de fé irracional [...].”

Ou seja, a retribuição pura e simples não consegue fundamentar a necessidade de punição do autor, uma vez que coloca o Estado numa posição também de algoz, na medida em que infringe um mal (sanção penal) a um cidadão seu, sem nenhuma finalidade social que justifique tal intervenção malévola e “[...] esta visão viola flagrantemente a dignidade da pessoa humana, pois não se pode entender que a pena seja aplicada apenas para retribuir um mal, sem que o mal da pena sirva para qualquer propósito" (MELLO, 2010, p. 339).

Já as teorias preventivas "[...] têm o mérito, como sustenta Ferrajoli, de voltar-se para o futuro, excluindo as penas socialmente inúteis, que são aplicadas como retribuição ao mal passado" (MELLO, 2010, p. 342). Elas se dividem em dois grupos: prevenção geral, no seu viés positivo e negativo, e prevenção especial, também analisada sob a ótica positiva ou negativa.

Os defensores da prevenção especial positiva justificam a necessidade da pena acreditando no seu efeito ressocializador, pois creem que por meio da pena o infrator irá internalizar valores estabelecidos pela sociedade de modo a voltar a inserir-se nela novamente para conviver de forma harmoniosa para com seus pares.

Ocorre que inúmeras críticas são apontadas pela doutrina a esta teoria, a começar pelo questionamento da própria legitimidade do Estado para educar seus cidadãos, de modo a fazê-los internalizar valores e apreender padrões de condutas impostos por uma minoria, transformando-lhes seu caráter e sua personalidade. Ademais, esta teoria também não consegue explicar o tempo que demandaria para transformálos na "prática do bem", segundo medidas socialmente aceitáveis.

Nesse sentido, Ferrajoli (apud QUEIROZ, 2001, p. 62-63) 
afirma que:

O Estado, que não tem o direito de forçar os cidadãos a não serem malvados, senão só impedir que se danem entre si, tampouco tem o direito de alterar - reeducar, redimir, recuperar, ressocializar ou outras idéias semelhantes - a personalidade dos réus. [...] As penas, consequentemente, não devem perseguir fins pedagógicos ou correcionais, senão que devem consistir em sanções taxativamente predeterminadas e não agraváveis com tratamentos diferenciados e personalizados do tipo ético ou terapêutico.

Roxin (1998, p. 21) chega a afirmar que "[...] a teoria da prevenção especial tende, mais que um direito penal da culpa retributivo, a deixar o particular ilimitadamente à mercê da intervenção estatal".

A teoria da prevenção especial negativa defende que os desviados devem ter seus comportamentos neutralizados, devem ser inocuizados, para que não voltem a reincidir em infrações penais. Porém, tal teoria também sofre críticas da doutrina, na medida em que não consegue explicar a imposição de penas em crimes não repetíveis, como, por exemplo, um homicídio passional.

Nestes casos, se poderia prescindir da pena, mesmo que estes fossem delitos de grande gravidade? Em outras palavras, apesar do crime existir, o autor deste ficaria imune à ação estatal, na medida em que não oferece mais perigo para a sociedade, não havendo necessidade de neutralizá-lo, inocuizá-lo.

Por fim, tem-se a justificativa da pena pela perspectiva da prevenção geral, seja ela positiva (reafirmação da norma jurídica) ou 
negativa (intimidação), teoria esta que, sem sombra de dúvida, tem um maior número de adeptos na doutrina especializada, notadamente, porque sua justificação está adstrita ao Estado Democrático de Direito.

Pelo viés positivo a pena se justifica na medida em que reestabelece a credibilidade da norma jurídica, tendo esta sido violada quando do cometimento do delito. Dito de outra forma, o ordenamento jurídico, plexo de normas regulativas de comportamentos, imprescindível na manutenção da ordem do Estado, seria reafirmado, a partir da punição daquele que rompeu temporariamente com a ordem instituída, reafirmando, dessa forma, o Estado Democrático de Direito.

São adeptos desta teoria "[...] Noll, Roxin, Shunemann e Hassemer, em sentido de motivação para a justiça normal [...]. Jakobs e Achenbach no sentido funcionalista-sistêmico" (PÉREZ MANZANO, 1990, p. 131).

Pelo aspecto negativo a prevenção geral tem por fim aplicar a lei penal sobre o infrator visando intimidar os demais membros no cometimento de delitos; dito em outras palavras, a punição exemplar do delinquente serve como contra-motivação da ação delituosa.

Acredita-se que por meio das normas postas pelo direito penal os cidadãos irão dissuadir da vontade de cometer crimes, uma vez que ficarão intimidados com a possibilidade de serem penalizados, estereotipados socialmente como "criminosos", de onde deriva sua utilidade social.

Nas palavras de Queiroz (2001, p. 48), a prevenção geral negativa tem por função a "[...] dissuasão de comportamentos delituosos, ou especial, destinada a demover os potenciais infratores".

São adeptos desta teoria na doutrina, hodiernamente, "Danner e Gimbernart, Luzón, Muñoz Conde, Mir, Octavio de Toledo e Huerta” (PÉREZ MANZANO, 1990, p. 131). 
Assim, numa rápida síntese se pode constatar que a pena pode ser justificada tanto pela teoria retributiva, quanto pelas teorias preventivas (geral ou especial), podendo, ainda, ter uma fundamentação mista, na medida em que combina as teorias acima esposadas, como é o caso do Brasil, consoante se depreende do art. 59 do CP, a saber:

O juiz, atendendo à culpabilidade, aos antecedentes, à conduta social, à personalidade do agente, aos motivos, às circunstâncias e conseqüências do crime, bem como ao comportamento da vítima, estabelecerá, conforme seja necessário e suficiente para reprovação e prevenção do crime (BRASIL, 2005)

\section{TEORIAS DESLEGITIMADORAS DA PENA}

Existem algumas teorias que, contrariamente as supracitadas, deslegitimam a aplicação da pena num Estado Democrático de Direito, fazendo uma leitura às avessas das já apontadas. Estas correntes representam:

Movimentos de política criminal, vertentes da assim chamada nova criminologia ou criminologia crítica, surgida nos Estados Unidos por volta dos anos 60 e 70, que, rompendo com a criminologia tradicional (a criminologia positiva), e sob o influxo de teorias sociológicas principalmente (das mais diversas tendências), contrapõem ao paradigma etiológico, próprio da criminologia positiva, um novo paradigma, o paradigma do controle (QUEIROZ, 2001, p. 90-91). 
Apesar de possuírem a mesma base teórica as correntes delesgitimadoras da pena são bifurcadas em duas vertentes, a saber: minimalismo e abolicionismo penal, guardando dinâmicas próprias e consequências, ao menos em curto prazo, diversas.

O minimalismo penal legitima a pena como ultima ratio, ou seja, quando nenhum outro ramo do ordenamento jurídico solucionar o conflito existente, o direito penal estará legitimado para intervir. Nas palavras de Queiroz (2001, p. 105-106):

[...] diferentemente do abolicionismo, o minimalismo penal aqui tratado, embora partilhando, em geral, da crítica abolicionista, propõe, imediatamente, a máxima contração do âmbito de atuação do sistema penal, preservando-o, assim, residualmente, e só mediatamente a abolição - a longo prazo - desse subsistema de controle social.

O abolicionismo, ao revés,

[...] recusa consistência científica a todas as premissas sobre que descansa o direito penal, e propõe, por isso, não apenas a extinção da pena, nem do direito penal, mas a imediata abolição de todo o sistema de justiça penal (QUEIROZ, 2001, p. 92-93).

Hulsman (1997, p. 190), um dos principais representantes do abolicionismo penal defende que a terminologia punição é utilizada numa acepção errônea pela justiça criminal, uma vez que "[...] é somente 
na relação entre o "punidor" e o "punido" que se encontra o caráter de punição", revelando por meio desta lógica que o que ocorre nas agências de controle formais é, em realidade, violência, devido ao caráter estrutural sobre o qual o modelo penal encontra-se estatuído.

Chama um evento criminalizável pelo Estado de "situaçãoproblemática" e reivindica que a mesma seja resolvida pelas pessoas envolvidas, perguntando-lhes:

[...] o que aconteceu, de que maneira eles se sentiram ou se sentem injustiçados por ele, a quem ou a qual "estado de coisas" eles atribuem responsabilidade pelo evento, o que desejam fazer a respeito dele e/ou o que eles querem que seja feito por outros (HULSMAN, 1997, p. 206-207).

Propõe uma maior aproximação do ofensor e do ofendido, de modo que a solução encontrada seja eficaz para ambos e não violenta para as partes envolvidas, o que acaba por deslegitimar todo o sistema punitivo na resolução de conflitos.

Revela que a estrutura do sistema repressor não oferece nenhuma aproximação entre a vítima e o seu ofensor ou, quando oferece, o faz muito timidamente. Ao mecanizar sua lógica de resolução de conflitos, principalmente por meio da divisão de trabalho dos profissionais que lá se encontram, acaba suprimindo possibilidades reais de interação entre as partes que poderiam ser bastante proveitosas e instalando, em seu lugar, resoluções pré-fabricadas nos moldes cartesianos para o término das situações-problemáticas o que, na prática, acaba sendo contraproducentes, uma vez que ocorre uma "[...] pacificação artificial da violência sem que 
a satisfação tenha chegado aos que vivenciaram o problema." (SILVA, 1997, p. 216).

Assim, " $[\ldots]$ ao invés do sistema penal resolver os problemas a que se propõe, ele cria novos, além de agravar os já existentes. [...] A abolição pressupõe a criatividade, deixando de lado o automatismo da subsunção do fato à norma" (SILVA, 1997, p. 215).

Por conta da própria idiossincrasia do sistema punitivo estatal os abolicionistas reivindicam a redução autoritária do Estado e uma maior amplitude de liberdade para a resolução de conflitos individuais, já que compartilham da ideia de serem mais eficientes no combate da criminalidade devido à interação proporcionada pela mediação e conciliação extra-estatal, além da menor exposição (publicidade) das pessoas envolvidas nestes eventos.

Hulsman, para reforçar seu argumento recorre, ainda, a existência da cifra negra já comprovada cientificamente pela criminologia crítica, realçando sua convicção científica de que boa parte das situaçõesproblemáticas é resolvida sem conhecimento da justiça penal, o que faz com que este instrumento de controle social seja ainda mais ineficaz na sua função declarada de combate e prevenção da criminalidade.

Por outra via, a deslegitimação do sistema repressor se dá, para Hulsman (1997, p. 195-196), já no âmbito da criminalização primária, no momento da seleção do quê criminalizar e do quantum de pena proposta, uma vez que não há nenhuma lógica interna para explicar a atividade legislativa na tipificação de situações-problemáticas, pois:

Possuem propriedades separadas e nenhum denominador comum [...]; nenhuma estrutura comum pode ser encontrada na motivação daqueles que estão envolvidos em tais eventos 
[criminosos], nem na natureza das conseqüências, nem nas possibilidades de se lidar com eles [...]. Tudo o que estes eventos têm em comum é o fato de que o sistema judiciário está autorizado a tomar providências contra eles.

Denuncia, dessa forma, a arbitrariedade do sistema punitivo estatal, sua seletividade intrínseca, sua violência estrutural, reforçando sua tese abolicionista de todo o controle de justiça criminal.

Ademais, ao reconstruir o cenário do crime, o sistema penal acaba por criar personagens fictícios, secundarizando o papel da "vítima" ao mesmo tempo em que reflete seus holofotes sobre os "criminosos", tendo por consequência a inconsistência da própria justiça criminal já que:

A consistência da escala dentro do sistema leva necessariamente a inconsistências com as escalas daqueles diretamente envolvidos fora do sistema, já que valores e percepções numa sociedade não são uniformes (HULSMAN, 1997, p. 199).

Por fim, afirma que:

A criminalização é injusta, já que, através de sua própria estrutura, nega as variedades existentes na vida social e os diferentes "significados" daí gerados, e porque ela é incapaz de percebê-los e lidar com eles. É injusta, também - em seus próprios termos - porque não consegue lidar igualmente com agressores e vítimas: a maioria deles nem mesmo aparece na justiça criminal (cifra negra); regra geral, são lidados em algum outro lugar de uma forma que não é sequer 
conhecida pela justiça criminal (HULSMAN, 1997, p. 206).

Neste mesmo diapasão afirma Silva (1997) ao revelar que quando levados para o sistema de justiça penal os fatos criminosos (minoria esmagadora de situações-problemas) estes não são trabalhados em sua essência; o que é levado primordialmente para a resolução de conflitos na estrutura burocrática vigente é o procedimento que deve ser seguido rigorosamente sob o discurso legitimador de seguir os princípios garantistas do Estado Democrático de Direito como o devido processo legal, a segurança jurídica, dentre outros.

A punição do "culpado" vai servir como "exemplo" para a sociedade e para ele próprio, justificando-se pela intimidação que isto deveria causar aos outros e pela inibição que deveria incutir no punido - efeitos que não consegue atingir. A "vítima", por sua vez, assume a posição de testemunha e sua vontade se não é totalmente desmerecida, é relegada a um segundo plano. Tudo isso em nome do procedimento e da perpetuação da burocracia estatal (SILVA, 1997, p. 215).

Por tudo já exposto, Silva (1997, p. 216) afirma em total consonância com Hulsman que a proposta abolicionista é, antes de ser utópica, criativa “[...] ao desmentir o que para muitos é natural e intocável: o sistema penal como única forma legítima de lidar com a violência”. E também propõe como alternativas ao sistema repressor estatal as possíveis respostas à violência social, tais como “[...] a terapêutica - não enquanto corretivo moral -, a educativa e a compensatória, tendo como pressuposto 
a conciliação" (SILVA, 1997, p. 217).

Porém, para que estas novas propostas/ respostas de solução de conflito sejam aceitas no âmbito social são necessárias duas posturas concomitantes: o abolicionismo acadêmico que "[...] implica uma mudança conceitual e de linguagem, evitando a reconstrução ilegítima das situações-problema como meros fatos criminalizáveis que precisam de uma resposta punitiva" e o abolicionismo como movimento social que “[...] inicia-se com mudanças de percepções, atitudes e comportamentos, negando a centralização do poder e a verdade ditada pela lei” (SILVA, 1997, p. 217).

\section{UM QUESTIONAMENTO ACERCA DA (DES)NECESSIDADE DA PUNIÇÃO}

Mas, afinal, por que punir? Esta é uma indagação que se faz há séculos e, talvez, uma das questões mais difíceis e controversas a ser respondida pela Dogmática Jurídico-penal, devido ao viés multifacetado que possui.

Devido às "[...] relações estreitas que a culpabilidade material tem com a pena, e, por consequência, com a dignidade humana" (MELLO, 2010, p. 329), privilegiou-se, neste artigo científico, tentar elucidar este questionamento a partir das teorias fundamentadoras da culpabilidade, bem como, das teorias legitimadoras da pena, fazendo um contraponto destas com as teorias deslegitimadoras da sanção penal, de modo a verificar a necessidade ou não da punição.

A imposição da pena pressupõe culpabilidade,

o conceito material de culpabilidade deve 
harmonizar-se com a finalidade da pena, que, por sua vez, está inserida num contexto maior, que é a missão do Direito Penal em um Estado Democrático de Direito (MELLO, 2010, p. 336).

Essa escolha se justifica na medida em que a legitimação do direito de punir num Estado de Direito só pode ser defendida a partir de dois pontos de vistas nitidamente entrelaçados, a saber: a) ou encontrando-se o fundamento material da culpabilidade para responder a pergunta do por que da imputação pessoal e da consequente restrição de direitos fundamentais, b) ou porque as finalidades da pena numa perspectiva utilitarista a justifica.

Roxin assevera que a culpabilidade não pode fundamentar a imposição penal, mas apenas limitá-la a partir de funções preventivas. Gimbernat chega ao extremo de propor a substituição da culpabilidade pela necessidade de pena; Jakobs afirma que a culpabilidade confunde-se com as próprias finalidades preventivas (MELLO, 2010, p. 333).

Quanto à justificativa da pena pela perspectiva do fundamento material da culpabilidade já se verificou, ao longo da explanação, que é inviável, na medida em que não tem como se provar a exigibilidade ou inexigibilidade da conduta diversa de alguém, devendo, por isso, esta opção ser descartada.

Deste forma, “[...] a justificativa da imputação da pena estaria fora da ideia de culpabilidade, que poderia ser nas funções preventivogerais positivas, como prefere Jakobs, ou nas razões de política criminal, 
como prefere Roxin” (MELLO 2010, p. 335).

Assim, resta apenas fundamentar a pena a partir dos seus fins, seja a) como castigo; b) para reafirmar os valores intrínsecos às normas jurídicas; c) para intimidar as pessoas de cometerem crimes; d) para ressocializar/ reeducar alguém desviado; e) para neutralizar as ações delituosas de um infrator.

Ocorre que como castigo a pena não mais pode ser sustentada hodiernamente, haja vista sua finalidade ter que estar atrelada à dignidade da pessoa humana, por conta da opção política feita pelos Estados contemporâneos que se auto definem como Democrático de Direito, uma vez que a retribuição, apesar de ter:

[...] o mérito de estabelecer um dever-ser proporcional entre a intensidade da pena e a medida da culpabilidade do sujeito [...] deixa em aberto em qual medida a culpabilidade fundamenta a pena, ou pior: fundamenta a pena a partir de critérios moralizantes (MELLO, 2010, p. 341).

Pelo mesmo motivo, deve ser rechaçada a aplicação da pena a uma determinada pessoa de modo a dissuadir as demais de cometerem delitos, pois esta ideia acaba instrumentalizando o homem que serve tão-somente como "bode expiatório" para atingir fins de prevenção geral negativa.

Pela mesma razão deve ser também descartada a tese defendida pela teoria especial positiva, na medida em que o Estado não possui legitimidade para corrigir, ressocializar, reeducar seus cidadãos de modo a fazê-los pensar e agir segundo padrões impostos por uma determinada 
parcela da população,

[...] pois um tratamento coativo das tendências criminosas pelo Estado viola a autonomia ética da pessoa e, por consequência, a dignidade humana. Além disso, a prevenção especial não permite delimitar um quantum da pena, podendo ser aplicada indefinidamente (MELLO, 2010, p. 345).

Por derradeiro também não pode ser aceita a teoria da prevenção especial negativa, não porque afronta a dignidade da pessoa humana, mas porque "[...] o propósito de evitar a reincidência já pressupõe a imputação do juízo de culpabilidade" (MELLO, 2010, p. 345), ou seja, "[...] a prevenção especial não pode fundamentar a imputação pessoal que constitui o seu pressuposto" (MELLO, 2010, p. 345).

Logo, em respeito aos direitos fundamentais do homem, a pena só pode ser sustentada a partir da teoria da prevenção geral positiva, já que compatível com os ditames constitucionais das garantias dos direitos humanos.

No que diz respeito àqueles que desacreditam na eficácia da pena, os argumentos utilizados para reivindicar sua abolição ou contração ao máximo são da seguinte ordem: a) é uma forma artificial de pacificação da violência; b) por ser artificial, não é eficiente, na medida em que o Estado monopoliza a lide e não dá oportunidade às partes de resolverem seus conflitos; c) contraria direitos fundamentais da pessoa humana na medida em que as expõem publicamente, estigmatizando-as perante a sociedade na qual também são partes; d) não combate, nem previne a criminalidade; e) é arbitrária, uma vez que criminaliza comportamentos 
indiscriminadamente.

São argumentos tão persuasivos quanto daqueles que sustentam a necessidade da pena, possuindo ambos rigor científico, na medida em que respeitam os pressupostos metodológicos da dogmática jurídicopenal e das ciências afins, como a criminologia e a política criminal, de modo a legitimarem-se e perpetuarem-se por séculos nas discussões acadêmicas e nas práxis dos tribunais.

Aliás, a legitimação do sistema penal decorre justamente por ser a dogmática jurídica eminentemente uma ciência discursiva, argumentativa, que utiliza em sua metodologia não a lei da causalidade, como o faz as ciências exatas, pois, se assim fosse, já teria sido suprimido do mundo natural, uma vez que:

[...] ainda hoje as pesquisas empíricas realizadas na Alemanha não conseguiram comprovar se o Direito Penal é eficiente aos fins propostos pela pena, quanto ao seu caráter preventivo, quer quanto à prevenção de novos delitos por terceiros respeitadores da lei, quer em relação à reincidência por parte do condenado (BICUDO, 2010, p. 165).

A inviabilidade de sua comprovação empírica certamente resvalaria na sua própria inexistência, haja vista sua indiscutível afetação nos direitos fundamentais da pessoa humana, na sua dignidade, sendo este fundamento basilar de um Estado Democrático de Direito devendo, por isso, ser sempre salvaguardado, independentemente das circunstâncias supostamente fáticas contrárias apontadas.

O próprio conceito de culpabilidade como pressuposto para a imputação da pena é um exemplo dessa afronta aos direitos fundamentais 
conforme já supramencionado, uma vez que se utiliza do conceito de "homem médio" para poder estabelecer um liame subjetivo entre o injusto e uma pessoa determinada, desconsiderando suas características pessoais e as peculiaridades da situação em que se encontra, já que tal fórmula “[...] desvincula o conceito de culpabilidade do conceito de pessoa, pois o que importaria, no caso, não seriam as características do agente, mas sim as características de um sujeito ideal inalcançável" (DIAS apud MELLO, 2010, p. 324).

Consoante aponta Mello (2010, p. 323), “[...] são inúmeros os direitos fundamentais constitucionalmente assegurados como as liberdades política, ideológica, religiosa, cultural, que asseguram ao sujeito o direito de ser diferente do padrão médio, sem que as diferenças sejam utilizadas para fazer recrudescer o juízo de culpabilidade."

Esta fórmula utilizada até hoje pela dogmática penal acaba pondo em xeque a própria coerência do ordenamento jurídico que, como uno e indivisível, deveria manter uma consistência lógica quanto aos seus pressupostos, não podendo, por um lado, garantir um catálogo amplo de direitos fundamentais para o homem e, por outro, impor-lhes padrões médio de condutas pré-determinadas de modo a homogeneizálos, servindo esta homogeneização como parâmetro valorativo para fundamentar a aplicação da sanção penal.

Ademais, até hoje também o conceito de culpabilidade encontrase imbrincado com o de castigo, de retribuição, ponto de vista ético este insustentável num Estado garantidor de direitos fundamentais, haja vista a carga moralizante que traz consigo, uma vez que estigmatiza: o sujeito como ser, como pessoa, pois assim the atribuem determinadas características de perversidade, que amiúde não possuem relação com o fato ilícito, ofendendo fragrantemente os princípios constitucionais 
de igualdade e dignidade entre as pessoas (BUSTOS RAMÍREZ; HORMAZÁBAL apud MELLO, 2010, p. 325).

Por isso, frente aos flagrantes desrespeitos aos direitos humanos delineados acima, se deve questionar se é legítima a intervenção estatal na restrição de direitos fundamentais do homem de relevância ímpar como, por exemplo, sua liberdade, de forma a verificar a necessidade ou não de aplicação de uma pena, uma vez que esta:

[...] encontra-se num permanente estado de tensão: de um lado, a ofensa à dignidade do infrator, em face de uma alegada proteção da dignidade dos demais; do outro, a proteção à dignidade humana, sobretudo em face da máxima de não-instrumentalização do homem (MELLO, 2010, p. 330).

Esta tensão da pena acaba se materializando em uma antinomia principiológica, na medida em que o poder punitivo terá que optar entre preservar a dignidade do infrator ou salvaguardar interesses sociais, de modo a sacrificar sempre direitos fundamentais em prol de justificar a sanção penal.

Uma possível solução para tal problema é a aplicação da técnica da ponderação, utilizada sempre que há conflitos de natureza principiológica, como parece ser o caso em tela, devendo o legislador optar pela resolução que traga a "máxima utilidade possível garantida à maioria formada pelos não desviantes [...] ao mínimo sofrimento necessário a ser impingido à minoria formada por desviantes" (FERRAJOLI apud MELLO, 2010, p. 342-343).

Mas será que também guarda correspondência com a dignidade da pessoa humana a visão utilitária propugnada pela prevenção geral 
positiva, em outras palavras, se pode aceitar que a pena imposta a um indivíduo concreto tenha como paradigma a necessidade social? Conforme Mello (2010, p. 349), “a prevenção deixa em aberto o fundamento da imputação, não conseguindo conferir sentido e conteúdo à imposição da pena".

Resta, portanto, declarar, que até o estágio atual de desenvolvimento da dogmática jurídico-penal, não se encontrou o fundamento material da culpabilidade de modo a convencer do por que uma pessoa deve ser submetida à violência estatal e ter seus direitos fundamentais vulnerados.

A pena não se justifica racionalmente nem cientificamente, apesar de sua intensa proliferação na contemporaneidade. O mal perpetrado por ela, notadamente quanto à violação de direitos humanos, certamente é maior do que o seu suposto bem produzido, razão esta suficientemente robusta para que o poder punitivo estatal reavaliasse sua utilização criteriosamente, de modo a ponderar se deve ou em quais situações utilizá-la.

\section{CONCLUSÃO}

Buscou-se, no decorrer deste artigo, compreender os pressupostos da pena no sentido de verificar quando uma pessoa é merecedora dela e, uma vez merecedora, quais as finalidades da pena, o que a sanção penal visa alcançar quando é aplicada.

Para tanto, discorreu-se sobre as teorias que fundamentam a culpabilidade do autor, desde a perspectiva tradicional - teoria psicológica da culpabilidade, teoria normativa da culpabilidade e teoria normativa pura da culpabilidade -, até a perspectiva contemporânea da mesma, 
esboçada por Jakobs, Roxin, Bustos Ramírez e Hormazábal Malarée.

Procurou-se, por meio deste resgate histórico, encontrar o fundamento material da culpabilidade de modo a sustentar racionalmente a imputação pessoal do injusto a uma pessoa determinada, dentro de uma lógica jurídica e científica, refutando princípios moralizantes incompatíveis com o princípio da autonomia ética pessoal.

Em seguida, buscou-se compreender a necessidade da aplicação da pena, analisando as teorias retributiva, de prevenção geral (positiva e negativa) e de prevenção especial (positiva e negativa), de modo a apreender seus pressupostos teóricos e verificar qual delas pode ser sustentada e validada num Estado de Direito.

Esboçou-se as teses deslegitimadoras da sanção penal, notadamente o abolicionismo e o minimalismo penal, de modo a contrapô-las às ideias totalitárias e hegemônicas difundidas na academia e nos manuais, demonstrando que também elas possuem legitimidade discursiva e fôlego argumentativo para sustentar a desnecessidade da punição.

Discorreu-se sobre os argumentos favoráveis bem como os desfavoráveis à intervenção do poder punitivo do Estado, tendo sempre como pano de fundo a dignidade da pessoa humana, haja vista ser este o alicerce do Estado Democrático de Direito contemporâneo, podendo a pena ser justificada somente e na medida em que é compatível com esta perspectiva axiológica.

Foi revelado que até a presente data as teorias fundamentadoras da pena, bem como o conceito material de culpabilidade, não conseguem explicar o porquê das restrições de direitos fundamentais, quando a violência estatal deve ser imposta, em quais situações o homem deve se submeter à voracidade do Estado. 
Por fim, buscou-se fazer uma reflexão acerca da necessidade da utilização da pena, tendo em vista os malefícios que ela carrega em contraposição aos supostos benefícios que ela declara, tendo por premissa a pessoa humana, sujeito e objeto das intervenções estatais.

\section{REFERÊNCIAS}

BICUDO, Tatiana Viggiani. Por que punir? Teoria geral da pena. São Paulo: Saraiva, 2010.

BRASIL. Decreto-Lei $\mathbf{n}^{0}$ 2.848: promulgado em 07 de dezembro de 1940. In: VADE

MECUM acadêmico de direito. 2. ed. São Paulo: Rideel, 2005.

BUSTOS RAMIREZ, Juan José; HORMAZÁBAL MALARÉE, Hernan. Lecciones de Derecho Penal. MADRID: Trotta, 1999. v. II.

FRANK, Reinhard. Sobre la estructura del concepto de culpabilidad. Buenos Aires: B de F, 2004.

GOLDSCHMIDT, James. La concepción normativa de la culpabilidad. 2. ed. Buenos Aires: B de F, 2002

GRECO, Luis. Introdução à dogmática funcionalista do delito. Disponível em: $<$ http://www.idclb.com.br/revistas/20/revista20\%20 (13).pdf $>$.

HULSMAN, Louk. Temas e conceitos numa abordagem abolicionista da justiça criminal. In: PASSETTI, Edson; SILVA, Roberto B. Dias da. Conversações abolicionistas: uma crítica do sistema penal e da sociedade punitiva. São Paulo: Instituto Brasileiro de Ciências Criminais, 1997. p. 189-213.

MELLO, Sebástian Borges de Albuquerque. O conceito material de 
culpabilidade: o fundamento da imposição da pena a um indivíduo concreto em face da dignidade da pessoa humana. Bahia: Juspodivm, 2010.

MORAES, Vinícius. Concepções iusfilosóficas do direito penal do inimigo: uma análise sobre os fundamentos da teoria de Gunther Jakobs. Revista Brasileira de Ciências Criminais: RBCCrim, São Paulo, v. 16, n. 74, p. 9-34, set./out. 2008.

PÉREZ MANZANO, Mercedes. Culpabilidad y prevención: las teorías de la prevención general positiva en la fundamentación de la imputación subjetiva y de la pena. 1990. Tesis (Doctora Es Derecho) Universidad Autónoma de Madrid, Madrid, 1990.

QUEIROZ, Paulo de Souza. Funções do direito penal: legitimação versus deslegitimação do Sistema Penal. Belo Horizonte: Del Rey, 2001.

ROXIN, Claus. Derecho penal: parte general: fundamentos. La Estructura de La Teoria Del Delito. 2. ed. Madrid, España: Civitas, 1997. Tomo I.

ROXIN, Claus, Problemas fundamentais de direito penal.

Tradução de Ana Paula dos Santos Luís Natscheradetz, 3. ed. Lisboa: Veja, 1998.

SANTOS, Ana Caroline Elaine dos. A criminalidade de colarinho branco como expressão da desigualdade no direito penal brasileiro à luz da criminologia. Itajaí: 2006, 142 p.

SANTOS, Juarez Cirino. Direito penal: parte geral. 4. ed. Florianópolis: Conceito, 2010.

SILVA, Roberto Baptista Dias da. Abolicionismo, criatividade e 
satisfação. In: PASSETTI, Edson; SILVA, Roberto B. Dias da. Conversações abolicionistas: uma crítica do sistema penal e da sociedade punitiva. São Paulo: Instituto Brasileiro de Ciências Criminais, 1997, p. 214-217.

WELZEL, Hans. El nuevo sistema del derecho penal: una introducción a la doctrina de la acción finalista. Tradução de José Cerezo Mir. Buenos Aires: Editorial B de F, 2004.

Como citar: PORTELLA, Alessandra Matos. Direito de punir: reflexos sobre os pressupostos e os fins da pena. Revista do Direito Público, Londrina, v. 12, n. 3, p.16-57, dez. 2017. DOI: 10.5433/1980-511X2017v12n3p16. ISSN: 1980-511X.

Recebido em: 26/06/2015

Aprovado em: 31/10/2017 